\title{
Learning for Employment: Challenges Encountered by Students
}

\author{
Eureka Mokibelo, Lovie Seru \\ University of Botswana, Gaborone, Botswana \\ Email: mokibeloeb@mopipi.ub.bw, seru@mopipi.ub.bw
}

How to cite this paper: Mokibelo, E. and Seru, L. (2020) Learning for Employment: Challenges Encountered by Students. Open Access Library Journal, 7: e6549.

https://doi.org/10.4236/oalib.1106549

Received: June 23, 2020

Accepted: July 20, 2020

Published: July 23, 2020

Copyright ( $) 2020$ by author(s) and Open Access Library Inc.

This work is licensed under the Creative Commons Attribution International License (CC BY 4.0).

http://creativecommons.org/licenses/by/4.0/

\begin{abstract}
This paper discusses the challenges that are faced by students at the University of Botswana in learning for employment. There has been a complaint from employers that the University of Botswana does not produce students who are ready for employment. Based on this problem, this study investigated learners' views on learning for employment so as to unearth challenges that students encounter in learning for employment. This study adopted a qualitative research approach and it used the open ended questionnaires, interviews and focus groups to tease out information from the University of Botswana students. Students who participated in this study were selected from different levels (year groups). The findings indicated that learners encountered challenges at various stages of their learning. Such challenges include but are not limited to: more concentration on theory than practice, large classes, lack of job opportunities, limited time for practice in the world of work and lack of supervision in attachment placement. The study concludes that a reflection is necessary for lecturers, the university and employees in various organizations to assist learners to gain skills for employment.
\end{abstract}

\section{Subject Areas}

Human Resource Management

\section{Keywords}

Learning, Employment, Challenges, Institution, Students, Lecturers

\section{Introduction}

It is the mandate of every learning institution to produce students who can contribute towards the development of the country, its economy, reforming the country, building on past successes, remediating failures and design pro- 
grammes that are implementable. In light of this, Botswana's learning institutions should strive to produce graduates who are job ready. The University of Botswana (UB) is one of the highest and oldest institutions of learning in Botswana. As reflected in its mission and vision statements UB advocates for excellence in learning outcomes, it therefore aims to provide excellence in the delivery of learning to ensure that the country is provided with talented, creative and confident graduates (University of Botswana, 2019) [1]. The university aspires to produce graduates who are confident, creative and can apply skills they acquired from learning at UB. In short, UB aspires to produce graduates who are ready for the job market. Furthermore, the University of Botswana believes that learning should assist students to realize their full potential and develop academically and personally. In this regard, the central focus of the institution is to create a learning environment that would ensure that it produces graduates who are well rounded and are thus able to fit into the world of work (University of Botswana, 2019). To achieve this, the university endeavors to ensure that there is a link between students' training and the job market. Because of this, the university and employers occasionally share knowledge, information, tools and experiences that can strengthen this link.

Despite the long standing collaboration between UB and employers, there has been a complaint from employers that the University of Botswana does not produce graduates who are skilled and ready for the job market. They complain that UB graduates require further training and retooling when they "enter" the job market. Based on this problem, the objective of this study was to unearth problems that could be leading to UB not producing graduates with qualities for fitting into the world of work for the viewpoints of students.

This paper is part of a larger study that investigated students' views on learning for employment at the University of Botswana. The idea was to find out from the students whether or not thought the University of Botswana was teaching and training them effectively for employment. The study focused solely on students because they are the legatees of the education at the institution; hence the essentiality of their voice in enabling the university to reflect on its pedagogical practices. This paper considers investigating the challenges that students encounter in learning for employment very important because upon completing their studies, students should participate fully in the development of the country's economy. They therefore need to have appropriate literacy skills, technical proficiency and higher productivity levels. Learning at the university or any higher institutions of learning should be geared towards ensuring impeccable performance in the world of work. For this to be realized, classroom instructions at institutions of higher learning "mirror" the demands of the world of work and expectations of employers. Any challenges that are bound to hinder this should be addressed.

\section{Conceptual Framework}

This paper used concepts such as labour market, occupational skills and youth 
unemployment as its conceptual framework. These concepts are used because they are related to issues that this paper is addressing right from the classroom, job market, manpower planning and realities on the ground.

\subsection{Labor Market Signaling}

The labor market signaling is a useful adjunct to traditional forms of manpower analysis. It advocates for the need for wage and employment trends not only to guide schooling and training decisions, but also to evaluate how well labour markets are functioning (Middleton 1993) [2]. The objective of signaling, according to Middleton (1993) [2] is that it can estimate whether or not there would be upward or downward pressure on the economic returns to investment in specific skills. Planners can monitor labour market conditions and evaluate training programs. They can also focus upon skills that are of strategic importance to economic development and that take a long time to acquire. The main indicators or labor market signals required are: wages, employment trends by education and training and occupational classifications, costs of specific education and training programmes, enrolment data for institutions, programmes of study, individual courses, 'help-wanted' advertisements in newspapers and professional journals, unemployment rates by education, skill, training, and occupation. A part of the labor market signaling technique is the need to identify types of skills that are required in the labour market. It is felt that the demand for occupations is a poor predictor of future labour market requirements for qualified labour, simply because occupations change with new technological innovations. However, any forecasting technique can compensated through the use of scenario analysis that is, providing a number of alternative forecasts under different assumptions. This pronouncement is important because it underlines the basic theoretical model of the World Bank, and most international agencies which adhere to the World Bank protocols. The World Bank's theoretical model emphasizes education and training qualifications more than occupations. However, there is nowhere in the Banking work where there is a list of skills that can be used as a basis for analysis. This lacuna means that no real alternative to an occupational classification has been suggested. Obviously, a fixed occupational classification over the years will ignore technological changes. However, there is no reason why these cannot be factored in, this is what the United States of America (USA) does in practice. This begs the question of which enterprises, what questions to ask them and also what responses should be classified. It also assumes that enterprises know exactly the sorts of occupations that will be in demand after a gestation period of 3 to 5 years, the time taken to place information gleaned from enterprises to policy makers who then determine the types of courses to run in training schools, and for this to be put into practice through training teachers, attracting and then training students.

One often hears that training needs cannot be assessed and therefore the best bet is to go and talk to a few enterprises to see what they want. In fact, the sim- 
ple-minded statement posed at the beginning of this paragraph summarizes exactly what enterprise surveys of training needs try and establish, and what labour market signalling tries to put into practice. We should also note that enterprises work in their own best interests and tend to have a very short-term perspective. Therefore, any information collected about enterprises perspectives needs to be supplemented with other pieces of information. A tracer survey of graduates helps to assess the efficiency of training schools and also to estimate the placement of graduates in jobs. This sort of survey is very difficult and expensive to carry out, but is an effective way of determining the efficiency of training school courses to meet the training needs of the society. Another way to introduce more qualitative and perhaps speculative ideas on future development of training needs is to ask the practitioners themselves, through a key informants' survey as mentioned above.

\subsection{Occupational Skills}

One of the most difficult areas in manpower planning is the allocation of jobs into an occupational classification. Occupation, according to the ILO (Hussmans, Mehran \& Verma, 1992) [3], refers to the kind of work done during the reference period by the person employed (or the kind of work done previously if unemployed), irrespective of the industry or status in employment of the person. Information on occupation provides a description of a person's job which, in turn, is defined as a set of tasks and duties which are carried out by, or can be assigned to, one person. Clearly the precise dimensions of a job are required when examining unemployment, wages and their evolution over time. However, the characteristics and type of job change over time as technology makes some jobs obsolete, refines others and creates new ones. In most developing countries, the occupations listed are normally too aggregated to provide a detailed list of unemployed by occupation that would allow training courses to be identified as a result of a manpower planning exercise. In Vietnam, for instance, only 32 occupations are listed in their annual labour survey covering such occupations as enterprise director, culture/art officer, mining/coal/oil technology related, machine-manufacturing/electric and electronic and others. While the number of occupations probably number in the tens of thousands.

Clues about occupations that are likely to be in demand can be obtained by looking at data on those with technical secondary education and zero unemployment levels. This actually occurred in Vietnam in eight occupational classifications, enterprise director, metallurgy/mould/coke refining, paper industry and related industries, building material production, printing, leather/artificial leather based, aquatic breeding and harvesting, lifting and machine controlling. These categories also have zero unemployment for those with university or college education. Thus, the sorts of occupations that in 1997 had zero levels of unemployment were those with high skill or higher education levels such as small or medium enterprise director, graphic design linked with printing, aqua- 
culture, high quality leather products, and high quality paper products. However, a weakness in this particular methodology is that the economy might not support these occupations in large numbers. Leather for instance is rare in Vietnam, and aquaculture requires unpolluted environment. Thus, before recommending these occupations too fervently, it would be useful to look at other labour market signals such as wage levels, growth in employment, and technological change in these occupational categories. For this would require more detailed occupational data plus associated socio-economic labour market signals.

Occupations are grouped together mainly on the basis of the similarity of skills required to fulfil the tasks and duties of the jobs. Two dimensions of this rather difficult to define concept are used: skill level, which is a function of the range and complexity of the tasks involved and skill specialization which reflects the type of knowledge applied, tools and equipment used, materials worked on or with, and the nature of the goods and services produced. Nevertheless, despite the attention to detail in the classification system, the largest source of error in occupational statistics lies in the shortcomings of the verbatim raw material as elicited and recorded in the field (Hussmans, Mehran \& Verma, 1992) [3]. Another source of controversy, carried out within the ILO itself (see also Standing, 1999), is about the notion of labour, work and jobs. People wish to work in jobs but do not wish to labour. However, the occupational classifications struggle to define occupation and have not yet started with the task of determining which jobs are work and which ones are labour.

To contextualize the occupation and skill concept to the problem under discussion, it is vital for the institution to liaise with parastatals, private organizations and the government to detail the demands of the job market with regards to the appropriate skills for relevant professions. The job market is complex and therefore has to constantly reflect on skill specialization, type of knowledge applied, tools and equipment used, materials to use to increase production level. The University of Botswana should be part of this network in order to produce appropriate skills because students need to have professional skills in order to perform their duties. Occupational skills have to be transferred from the classroom to the place of work. Payment of a salary should be on satisfactory conditions or even outperforming situations; hence rigid training is required to match the payment and job description.

\subsection{Youth Unemployment}

Youth unemployment seems to be a global problem, and the contributory factors are many. However, the most frequently suggested explanation is that young people are unemployed because they are unskilled. They are unskilled because they are untrained and are poorly educated. Thus, it has become common practice to assign a central role to education to solve the youth unemployment problem. Hopkins (1980) [4] argued that for developing countries to achieve full employment rate jobs will have to grow by $3.9 \%$ per year. At the beginning of 1982 , 
the total number of unemployed youth in the Western world was estimated to be 20 million, shared almost equally between North America and Western Europe. These average unemployment rates masked significant age/sex differentials: teenage unemployment rates are consistently higher than those of young adults, who in turn have higher unemployment rates than adults, while girls fare worse than their male counterparts. Massive youth unemployment is caused by a number of economic, demographic, educational, and attitudinal factors. Population growth also contributes to youth unemployment as do the changing attitudes towards work by women. The reasons for unemployment suggested here are no different from Botswana's. For example, Nthomang \& Diraditsile (2016) [5] state that youth unemployment in Botswana is created by unemployable and unskilled labour, lack of work experience, large size of the youth labour force, jobless growth rate state and failure to create jobs, absence of job creation plans amongst other things. Pettinger (2017) [6] argues that the reasons for unemployment in the United Kingdom are lack of educational qualifications, geographical unemployment, lack of graduate jobs, cultural and social factors amongst other things. Students from the University of Botswana are similarly affected by these. The job market bemoans that students are unskilled, untrained and poorly educated, hence, the youths of Botswana are roaming the streets unemployed. Although this could be brought about by other contributory factors, employers in Botswana lament that the youths are unemployable. Therefore, the three concepts discussed above basically form the challenges faced by students in learning for employment.

\section{Research Methodology}

This study adopted the qualitative approach to investigate the views of students on learning for employment at the in the Communication and Study Skills Unit (CSSU) at the University of Botswana (UB). The CSSU is a department that has unique characteristics which teaches first year students but there are students who are taking the course as second, third and fourth years. The study targeted the second third and fourth year students and ignored first years because they were still getting grounded with university education. The study targeted students from second, third and fourth year across the faculties from the CSSU. Students are the beneficiaries of the courses taught at UB. It was therefore necessary to get their views regarding whether or not they think and believe they are effectively taught and trained for employment. The lecturers were deliberately left out given researchers' heuristics that would be objective, they would defend their positions.

A sample of 60 out of 150 students was selected from the faculties of Science, Education, Business, Social Sciences, Humanities and Engineering. This is a limited percentage of forty percent. These were students who have been to internships, attachments, teaching practice or in the job market before. Ten lecturers were issued with open ended questionnaires to give to students in their 
classes. Some of the lecturers had two classes and therefore sampled from the two classes. Most of the classes had thirty to forty students, hence, the sample was based on one third or one quarter of the class depending on whether students had been to an attachment, internship, teaching practice or has worked before. In this regard, convenience sampling was followed by lecturers in their classes. Issues of gender equity were not a problem because in each class there were both males and females who answered the questions. It did not appear from the answers that there were any serious issues related to gender equity.

Open-ended questionnaires, focus groups and interviews were used to collect data. Students were asked the following questions: What are your views on learning for employment? What measures/strategies have been in place to teach for employment? What challenges do you face when learning for employment and how do you think those challenges can be addressed? This paper focused only on the challenges students encountered in learning for employment. The data collection tools were triangulated for reliability and validity purposes to make sure that data can be reliable. In this regard, the data collection tools painted the same picture that indeed there were challenges in various faculties and they were different depending on the faculties. Focus group sessions were done with two classes from social science and humanities and the results were not different from what students said in questionnaires and interviews. Interviewed students were sampled from six classes and therefore the researchers did face to face interviews with ten students. The results of the interviews confirmed what students said in the open ended questionnaires and focus groups.

Data were analyzed according to each key research question to make sure that all questions have been adequately answered. Answers were tabulated according to major and minor themes and were coded according to faculties and themes. A pattern on emerging themes and sub-themes showing challenges students encountered in learning for employment was developed and hence this paper.

This study had limitations. Two faculties were not involved in the study and it is possible that they could have influenced the results of this study in one way or the other. However, this does not mean that the available data cannot be shared with educationists. The researchers do not intend to generalize the information to faculties which did not take part in this study because their situations might be different. Further, this study did not involve lecturers for the simple reason that they could defend their position and professions as lecturers at the University of Botswana. Therefore, it was important to hear their views about the challenges they encounter in learning for employment.

\section{The Results of the Study}

This section presents the results of the study. The section presents the challenges encountered by students in learning for employment. The histogram (Figure 1) below indicates responses to the question on challenges encountered by students in learning for employment from students across the different faculties. 


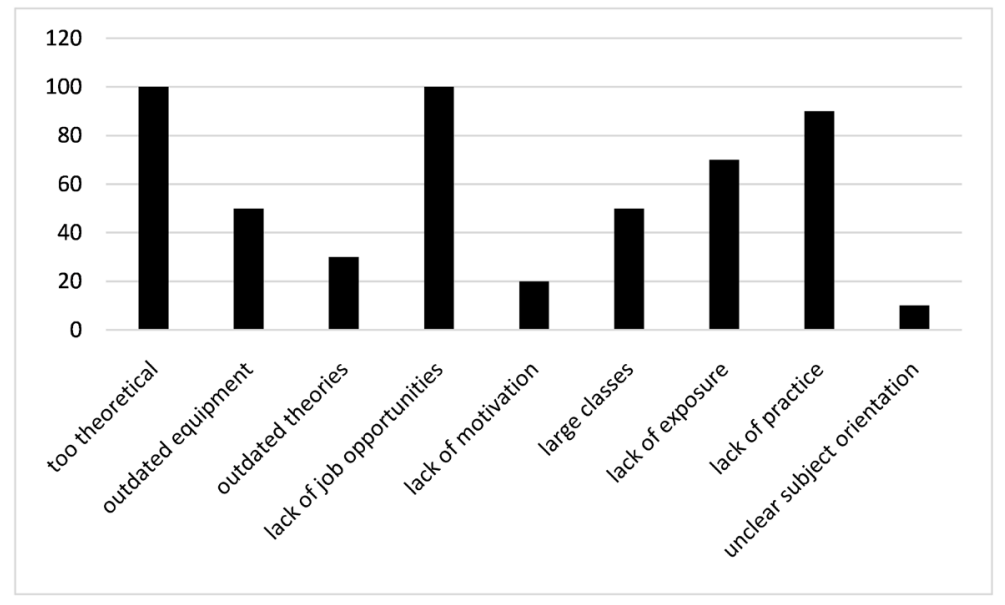

Figure 1. Challenges in learning for employment at University of Botswana. Source: data collected 2019.

From the graph above, the challenges that were reported by the students have been tabulated. The respondents across faculties reported that they were given too much theory with minimal practice during lessons. Some students complained that theory is not implementable. To further support this point one of the students said, "Sometimes we are taught things that we are not going to use in the world of work," Another one said, "we do the course to complete it rather than learn." This suggested that students want to be given more practical work than theory. However, the students from the Faculty of Education had a different view because many of them said that they get involved in teaching practice which gives them time to explore and experience teaching before they get posted to schools to teach.

Respondents (30\%) from the Faculty of Science and Engineering reported that the equipment they use for learning is no longer effective because it is outdated. One of the Engineering students said, "there is no adequate time for us to fully learn to operate some of the equipment." Another one said, "some of the materials are not up to date" Students further said, "there are inadequate resources to learn individually during practical sessions ... there is a shortage of laboratory apparatus ... and many equipment are old and outdated ..." This suggested that doing some experiments with old or faulty equipment could result in giving inaccurate information or results.

Many students across the faculties reported that during orientations some of the lecturers did not clearly explain what each subject entailed and what outcomes were expected from students. It was as a result difficult for them to make appropriate decisions. This could be linked to the issue that when some lecturers teach they do not follow and they do not understand. This suggested that it is vital for lecturers to adequately orientate students on the courses they will be reading for and adequately articulate the outcomes.

The lack of job opportunities was a common response from students across faculties. All the students reported that they were worried by the high rate of 
unemployment in their country. In this regard, students reported that there was no liaison between the university and potential employers. As a result, it was difficult for them to access and learn important work techniques. Consequently, students left the university inadequately trained. This suggested that students were worried by the fact that unemployment was high and they believed that the way they were trained contributed to it.

Some students from the faculties of Education and Humanities reported that there was no motivation to move on and listen attentively to lecturers. Other students also linked this problem to that of interpersonal skills. They argued that the lack of motivation also leads to the lack of interpersonal skills and communicating with others. To support this, one student reported that, "we have difficulties getting along with others because we come from different backgrounds". This suggested that some lecturers might not be reinforcing graduate attributes to students.

Respondents from the Science faculty reported that in some cases there were too many students in one class such that it became difficult to do practical work in laboratories and presentations during lessons. The high number of students in a class could be a problem especially in skills oriented and practical courses. This suggested that large number of students compromised the quality of experiments undertaken in laboratories in terms of time. Lecturers might be at a dilemma because it might take long for students to do experiments in the labs. Again, it may be difficult to do effective presentations because students had to be lumped together in groups and this might make it difficult to give each student a chance to present.

Some students in the Engineering and Business faculties reported that they did not do field work as early as level 100 (year one). Field work is introduced late and this does not give them enough exposure for work environment. One student reported that, "there are no field tripsandno attachments for BSc gener$a P$ '. This suggested that students felt inadequate to enter the job market due to inadequate exposure to field work.

The other challenge raised by students was that internship programmes had misplaced objectives. They were not relevant. They were also too short and unsupervised. In cases where there was some practice, it was too short and in some cases not relevant to what they did. This suggested that students were not happy with the internship programme.

\section{Discussion of Findings}

This section discusses the findings of the study on the challenges students encounter in learning for employment.

\subsection{Theory versus Practice}

The findings indicated that students grapple with too much information and courses that are theoretical. They therefore lamented that they needed practice 
to fit in the world of work. Costley \& Armsby (2007) [7] argue that learners do not want to study content which is packaged in artificial silos of disciplinary knowledge. They want to have content that is directly related to their work, and assessments that involve applied projects. In this regard, academics should mentor, coach and supervise hands-on assessments rather that spending too much time teaching theories that often fail to represent realities in the workplace (Costley \& Armsby, 2007) [7]. On the other hand, being given information and knowledge is necessary at tertiary learning. The knowledge may not be applicable at the time it is imparted, but students may need it at one point in their social and career life. However, some students appreciated the fact that learning comes only once, but they will use the theory for lifetime. As a way of addressing the problem of too much theory, the students suggested that there should be changed in the way learning programmes are administered to make them as practical as possible. According to the students, the four year programmes should be divided into half, two years of theory and two years of practice, and then a semester to discuss field work and write reports about their experiences.

\subsection{Large Classes}

The findings also revealed that the University of Botswana classrooms are highly packed with students. According to the students, large classes make it difficult to conduct experiments. Furthermore, the students could be too many for supervision and monitoring during internships and attachments. Scholars argue that large enrollments promote student disengagement and feelings of alienation, which can erode students' sense of responsibility. It can also lead to behaviors that both reflect and promote lack of engagement (Brady, 2011) [8]. Cheating can become a problem and logistics can also be a challenge when teaching a large class (Lynn, 1998) [9]. Large classes can be a problem, especially when it comes to practical work in laboratories or field work. Lecturers are unlikely to implement high-quality teaching techniques. It could also affect staff employment and this means that the university should have more manpower to give the students the attention they deserve. Even doing experiments for practical subjects becomes a challenge. It is a challenge to assist students doing practical work when classes are large. Effective teaching and producing learning is critically constrained by large classes and the students' perception about large classes being negative (Fortes, \& Tchantchane, 2010) [10]. In this regard, the students suggested that the university should reduce the number of intakes. The students suggested that the university should reduce the number of intakes so that available resources could be enough for fewer students.

\subsection{Outdated Equipment}

The findings of the study revealed that the university has a challenge in the procurement of new equipment especially for science laboratories. According to the students, some of the equipment that they were using were outdated and no 
longer working. Onto (2016) [11] argues that every institution needs to access up-to-date equipment to operate to its full potential. Even though every asset has a life cycle, institutions want to get the most out of their equipment going beyond their natural life span and can harm learning. It should therefore be mandatory for the university to buy new laboratory equipment as the old ones can limit teaching and learning. Although Onto (2016) [11] argues on behalf of businesses, his pronouncement also relate to teaching and learning. He points out that using old equipment comes with risks: there are risks of losing data; having data corrupted, being unable to carry out experiments, struggling to arrive at accurate results, time wasting in addressing the challenges and poor equipment performance. These can potentially hurt the teaching and learning, affect students' morale, and result high maintenance costs. This resonates with Work's (2019) [12] argument that there could be limited availability of spare parts, costs of outdated parts, limited support from original manufacturer and lack of trained experts to make specific repairs. According to the students, the world has gone digital. Thus, if some of the machinery and tools used in laboratories are manual, they could cause unnecessary delays and inaccuracies; hence making it too demanding to arrive at possible conclusions in the experiments carried out.

\subsection{Unclear Subject Orientation}

The findings showed that one of the challenges encountered by students was that they were not given enough information or orientation in some subject areas. To 'orientate' is to adjust to new circumstances, surroundings and or facts or make something suitable for a particular group (Macquarie Dictionary 2000). Marcum \& West (2004) [13] suggest that it is vital to use structured, progressive orientation programmes as these could boost students' self-esteem, critical thinking as well as self-management. There are reasons for orientating new students and these include: developing greater knowledge of the institution; creating attitudes that may enhance students' performance, adjusting and remaining with the organization, promoting behaviors that can lead to personal and organizational effectiveness and offer graduate support (Ross \& Clifford 2002) [14].

Orientations at the University of Botswana are done at the beginning of each academic year, a week before lessons start. Each faculty orientates its students on how things work at the university and to give students a chance to meet other students. It can be unfortunate if students are not appropriately orientated on what to expect in their courses. According to students this would be a problem because it normally takes them time to understand what the courses are about, what is expected of them, how they could be assisted and how they should learn. However, for different reasons, there are students who are admitted late into the institution. Such students miss the orientations and therefore end up taking long to settle in the university life. According to students, transition from the secondary school education to tertiary is critical and it has to be planned so that 
they do not get lost within the structures of the university.

\subsection{Saturated Job Market}

The findings showed that students' main worry while at the university was the prospect of not finding jobs upon completion of their studies. Students view this as an issue that defies the very purpose of learning for employment. Mourshed, Isherwood, Jaffer, Lim, Cardoso, Fennell \& de Moura Castro (2014) [15] point out that Japan has 700,000 young people who stay at home and have withdrawn from society. The same problem has been identified in North Africa and United States of America. In Greece, Spain and South Africa more than half of young people are unemployed. Governments have developed effective responses to unemployment but the problem still persist. Even though many young people cannot find jobs or quality jobs, many employers cannot find the right people to fill existing jobs (Mourshed et al., 2014) [15]. In order to address this problem, employers need to have an input in what goes into the university academic programmes. Mourshed et al., (2014) argue that it is difficult to understand which practices are most promising and what will it take to train young people sufficiently for them to become productive participants in the job market [15]. Mourshed et al. (2014) indicated that academics hardly ever know what happens to their graduates because they do not consider it important even though they should have the knowledge about job placement, job openings or wages and advise their students accordingly [15].

This study also revealed that students choose their courses without any pre-knowledge of whether or not they will be in demand upon completion of their studies. Further, the study has revealed that employers place high value in soft skills and yet they are difficult to define, distil and measure. The system is also failing students because most of the people who succeed are the wealthiest, oldest and well known politicians. The rest are those that are disheartened. Although there could be opportunities for self-employment, students do not see this as an option because they can't tolerate inherent bureaucratic procedures, corruption and the lack of transparency in awarding funds for small entrepreneurships, projects and other initiatives that they can embark on. According to the students the government should be flexible and offer relatively cheap assistance that does not require strict procedures. According to students the government could monitor their projects and advise accordingly in order to boost their profits.

\subsection{Unavailability of Opportunities to Do Field Work}

The findings revealed that students are not adequately exposed to formal employment. They do not do field work, and as a result not get grounded on what is happening in the job market. Not giving students' opportunities to do fieldwork limit their application of knowledge. It could also be a burden on the employer in terms of training newly recruited personnel. The study subjects suggested that 
the university should arrange with industries send students to them every year during the winter break until they graduate for them to gain experience and exposure to practical work. They posit that the exposure would assist them to get necessary experiences of life in the workplace. Students suggested that in addition to field work, there should be weekly or fortnight seminars or workshops where presenters talk to them about what is expected in the world of work. This would entail the university having to restructure their programmes. Furthermore, it would require lecturers reconciling what is needed in the world of work and what they teach at UB. This can be achieved through liaising with different stakeholders on learning for employment so that they can get to know the demands of the market and then align their programmes to what employers want. Doing this would actually be an investment on the students' education in that it would them an opportunity to explore the world of work. Students who participated in this study also suggested that the University of Botswana should bench mark from other countries and universities to learn how students are assisted to learn for employment.

One observation worth making is that when students were in the field for internships and attachments, employees at the companies they were attached to did not fully engage them, thereby making it difficult for them to acquire experience and skills. Billet and Choy (2013) [16] argue contested workspaces restrict others by creating boundaries that constrain and limit those who are perceived as threats or rivals and these could include personal facts. More experienced workers can inhibit access for those who are learning through the lack of appropriate support (Fuller \& Unwin, 2002) [17]. Unless students secure adequate experiences and support in the workplace and access opportunities to integrate content in their educational programmes and real work experiences, it might be difficult to reach the goals and expectations of employers. In this regard, guided learning at work is critical. In ideal work environments, more experienced workers have to act as models, coach, allow students to ask questions, interrogate issues and reflect on whether or not what they do could provide a rich learning working environment (Billet \& Choy, 2013) [16].

\subsection{Computer Literacy}

One of the challenges students lamented about was lack of knowledge on the use of computers. They indicated that lecturers take it for granted that they know how to use computers. Despite not having been trained on how to use computers, they are given assignments or tasks that require them to use computers. Oseghale and John (2014) [18] believe that computer literacy is the bedrock of sound academic performance because it enables students to use Internet facilities, access information and later process it. Therefore, students ought to have been exposed to technology in the classroom in order for them to have computer knowledge. Oseghale and John (2014) [18] argue that it is the responsibility of all educators to facilitate computer literacy because society cannot grow to its fullest 
without computer literacy. Billet and Choy (2013) [16] argued that the introduction of new media technologies for conducting work activities require understandings and ways of knowing and working that are quite distinct. For example, Lewis (2011) [19] posits that digital technology in the world of work demands that drivers, health workers, administrative work, technical work and hygiene standards of processing foods, and hotel settings should extend to clients, patients and customers. These changes require that learning acquired for entry into the world of work should be technologically based and be sufficient for lifetime employment. Regarding this challenge, students suggested that lecturers should not take for granted that all students are computer literate. As a result, lesson instructions of computer technologies should be made part of the curriculum.

\section{Implications}

The fact that there are challenges that impede effective teaching and learning means that funds are needed to address some of the challenges encountered by students. However, unavailability of funds to buy new equipment for laboratories and classroom equipment could mean that students would lag behind in terms of the use of technology. This would also impact on delivery of instructions in lecture rooms.

The findings also have implications for the students. Large classes have an impact on effective teaching and learning. This could mean that due to large classes, lecturers are unable to give students individual attention. On account of large classes some lecturers resort to giving students too much theory than practice and the results in students have a burn out. Again, the unavailability of job opportunities could lead to students losing interest in learning because of the knowledge that they might not find jobs upon completing their studies.

The findings also have implications for further research. Another research is needed to solicit information from the lecturers on learning for employment at the University of Botswana. They may have a different view from what students say.

\section{Conclusion}

Basing on the findings, students experience some challenges as they learn for employment. These challenges could be addressed by the university management, teaching staff and authorities for Tertiary Education. These challenges impact on the outcomes of learning as well as the students. The University of Botswana's learning culture and a shared vision and mission could propel a prompt response in making decisions that could enable students to fit into the world of work. Because of these, too much theory, large classes, out dated equipment, unclear subject orientation, lack of job opportunities, lack of exposure and lack of computer literacy should compel management and teaching staff to reconsider their practices in order to address students' challenges. Technology needs a concerted effort by all stakeholders to realize effective learning 
because it has become a complex phenomenon globally. All in all we can learn a great deal from what the students say are their challenges.

\section{Recommendations}

This study recommends that the university should review its policy on replacing old equipment in laboratories for students to move with modern technology and acquire accurate results from their experiments.

It is also vital for lecturers to supervise and monitor students when they have been assigned to various departments and ministries for attachments, internships or field work to maximize their learning. This could minimize students being assigned irrelevant duties and any form of abuse by their internal supervisors.

The University of Botswana should liaise with government and parastatals to discuss network and collaborate on students' learning for employment to close the existing gaps such as not knowing what the employer wants. The issue of unemployment should be addressed by both the university and the job market. The university could do more than it is doing right now.

There is need for each faculty to orientate students who are coming for the first time at tertiary to get acquainted with university learning from the onset. This should be the responsibility of each faculty to do the orientation in an organized manner to avoid students following programmes that they do not fully understand.

\section{Conflicts of Interest}

The authors declare no conflicts of interest regarding the publication of this paper.

\section{References}

[1] University of Botswana (2019) University of Botswana Calendar. University of Botswana, Gaborone.

[2] Middleton, J. (1993) Labour Market Signalling. http://www.unige.ch/cyberdocuments/theses2000/HopkinsM/these body.html

[3] Hussmanns, R., Mehran, F. and Verma, V. (1992) Survey of Economically Active Population, Employment, Unemployment and Underemployment. ILO, Geneva.

[4] Hopkins, M. (1980) A Global Forecast of Employment. International Labour Review, (Geneva, ILO), Sep-Oct. 1980.

[5] Nthomang, K. and Diraditsile, K. (2016) Improving Youth Employment in Botswana: The Need for Evidence-Based Policy and Programme Development. Mosenodi Journal, 19, 45-55.

[6] Pettinger, T. (2017) Causes of Unemployment. Oxford, UK 21st September 2017

[7] Costley, C. and Armsby, P. (2007) Work-Based Learning Assessed as a Field or a Mode of Study. Assessment and Evaluation in Higher Education, 32, 21-33. https://doi.org/10.1080/02602930600848267

[8] Brady, B. (2011) Managing Assessment in Large EFL Classes. In: Coombe, C., et al., 
Eds., Issues in Assessment, University of Michigan Press, Ann Arbor, 291-299.

[9] Lynn, C.E. (1998) Teaching Large Classes: Tools and Strategies. Sage Publications, Thousand Oaks.

[10] Fortes, P.C. and Tchantchane (2010) A Dealing with Large Classes: A Real Challenge. Procedia Social and Behavioral Sciences, 8, 272-280. https://doi.org/10.1016/j.sbspro.2010.12.037

[11] Onto, D. (2016) The Impact of Outdated Equipment on Your Business. https://www.linkedin.com

[12] Work, J. (2019) Five Reasons Outdated Manufacturing Equipment Equals Higher Maintenance Costs. https://www.manufacturingsuccess.org

[13] Marcum, E. and West, R. (2004) Structured Orientation for New Graduates: A Retention Strategy. Journal for Nurses in Staff Development, 20, 118-124. https://doi.org/10.1097/00124645-200405000-00003

[14] Ross, H. and Clifford, K. (2002) Research as a Catalyst for Change: The Transition from Student to Registered Nurse. Journal of Clinical Nursing, 11, 545-553. https://doi.org/10.1046/j.1365-2702.2002.00610.x

[15] Mourshed, M., Isherwood, T., Jaffer, A., Lim, C., Cardoso, B., Fennell, S. and Castro, C. (2014) Policy Debate/Education and Employment Mismatch. International Development Policy: Articles and Debates. https://doi.org/10.4000/poldev.1802

[16] Billet, S. and Choy, S. (2013) Learning through Work: Emerging Perspectives and New Challenges. Journal of Workplace Learning, 25, 264-276.

[17] Fuller, A. and Unwin, L. (2002) Developing Pedagogies for the Workplace. In: Evans, K., Hodkinson, P. and Unwin, L., Eds., Working to Learn: Transforming Workplace Learning, Kogan-Page, London.

[18] Oseghale, A.J. and John, O. (2014) The Impact of Computer Literacy on Students' Academic Performance in Senior Secondary Schools in Esan West Local Government Area, Edo State, Nigeria. Journal of Education and Human Development, 3, 265-270. https://doi.org/10.15640/jehd.v3n3a21

[19] Lewis, J. (2011) Dynamic Integrated Learning: Managing Knowledge Development in Road Transport. PhD, Griffith University, Brisbane. 